\title{
Chapter 7 \\ The Nexus Between Environmental \\ Changes, Culture of Migration, and Migration Aspirations
}

In this chapter, I delve deeper into the role played by 'cultures of migration' in the development of migration aspirations in both Tinghir and Tangier, and how these cultures of migration interact with environmental factors. This chapter builds further on previous insights from migration systems theory, which posits that migration results in multiple flows of material goods, ideas and money (Mabogunje 1970; Levitt 1998). In other words, this theory states that migration results in more than exchanges and flows of people. By building further on the concept of 'cumulative causation' (Myrdal 1957), migration systems theory advances that migration results in the transformation of social and economic structures, facilitating more migration. This idea is crucial to fully understand the development of migration aspirations because it pays attention to how contextual feedback loops can either positively or negatively stimulate the further development of migration aspirations (De Haas 2010). Hence, cultures of migration are established through the information sent by emigrants that have left a given region and provide feedback on their migration experiences in the country of destination to their migrant networks living in their region of origin and which ultimately result in shared ideas and beliefs on migration in a particular region (Timmerman et al. 2014).

To study how environmental migration and the development of migration aspirations linked to environmental change are impacted by the existing cultures of migration in Morocco, the two selected regions, Tangier and Tinghir, are interesting cases to compare. Both regions have faced significant out-migration in the past (Berriane et al. 2010, 2012). Nonetheless, the consequences of migration do not necessarily lead to the development of similar cultures of migration (Timmerman et al. 2014). This chapter's focus is of particular interest when studying environmental migration dynamics since environmental factors could strengthen existing migration dynamics and build further on existing migration flows. At the same time, environmental changes could be a factor that led people to migrate in the first place and have later resulted in additional migration flows due to contextual feedback mechanisms. 
A first objective of this chapter is to examine the differences in cultures of migration between Tangier and Tinghir. Tangier is an internal migration hub and gateway to Europe and hardly experiencing direct consequences of environmental changes. Tinghir is a local migration hub from surrounding desolate areas that also experiences significant out-migration to Europe and larger Moroccan cities, and where people are more directly confronted with environmental changes. The comparison of the development of cultures of migration and migration aspirations within two interconnected but distinct regions provides very useful information about the interplay between the different factors leading to (environmental) migration. In the second part of this chapter, more attention will be given to how these cultures of migration and migration patterns in general contribute to successful adaptation to environmental change.

A second objective of this chapter is to explore whether and how migration can be used as a successful adaptation strategy to deal with environmental change (Gemenne 2010) in regions that have been familiarized with migration in the past and in which the consequences of migration projects are already deep-rooted in everyday life and organization (De Haas 2006). The inclusion of the study of cultures of migration and migration dynamics is especially relevant in the Moroccan case due to their migration history and the gradual degradation of the natural environment. The progressive nature of environmental changes in Morocco makes it more likely that these changes coincide with societal changes and ongoing migration dynamics.

To summarize, in this chapter I focus on the origins of environmental migration in a region that has been subject to slowly-evolving environmental changes. Doing so will help shed a new light on the entanglement between cultural, economic, social, and natural factors and migration drivers. Therefore, taking a closer look at this complex set of factors and how they evolve over time is crucial to understanding vulnerabilities to environmental changes, resilience, and the development of migration aspirations for people living in these areas (Wisner et al. 2004).

\subsection{Migration Aspirations and Vulnerability to Environmental Change}

Earlier studies found that environmental changes put all other migration stressors under pressure (McLeman and Gemenne 2018). When looking at 'environmental displacement and migration' (Piguet et al. 2011; McLeman and Gemenne 2018), the notion of environmental displacement is mainly applied to situations in which abrupt environmental changes (e.g., floods, tropical storms, landslides) force entire populations to move, disconnecting this displacement from the will and aspiration to migrate due to 'external environmental factors and changes' that lie beyond the human will and capacity. The concept of environmental migration includes a wider array of human mobility trajectories as it encompasses the entire range of people 
who, due to some kind of environmental changes or factors, decide to migrate, regardless of the urgency of the displacement or type of environmental changes that lie at the basis of this decision (McLeman and Gemenne 2018). As I mainly focus here on the latter, which is especially relevant to the Moroccan case, this chapter helps to understand how migration dynamics gradually evolve and develop over time and are impacted by existing social structures.

The rather slow natural changes in Morocco allow more interference with other existing factors that determine whether or not people aspire or decide to migrate. The conceptual difference between abrupt and gradual changes to an individual's living environment is often very difficult to make and does not necessarily lead to clearly defined categories of types of migrants (e.g., climate change refugees vs climate change migrants; Bates 2002). This conceptual distinction matters especially to the extent to which people have time to prepare for migration, the clearly defined need to (immediately) migrate, and the perceived linkage between their migration aspirations and climate/environmental changes, as shown in Chap. 6. Furthermore, as I focus in this book on regions that can be both locations for in- and out-migration, this allows us to not only concentrate on people who have migrated for environmental reasons, but also on those who aspire to migrate due to environmental changes.

Investigation of the group that aspires to migrate, or those who would be very vulnerable to environmental factors but are not able to migrate, is methodologically very difficult (cf. 'trapped populations', Zickgraf 2018). Therefore, acquiring more insights into these groups is promising as it could help to gain more information to set up a broader framework on adaptation strategies to deal with climate/environmental changes and see migration only as one potential adaptation strategy amongst others. Processes preceding (environmental) migration are particularly hard to assess methodologically, which may be due to migration's interaction with the wider social context (Bates 2002; McLeman and Gemenne 2018). This is, for instance, clearly visible in research that links drought and desertification with migration across the globe, in which results are inconclusive and not straightforward (Piguet et al. 2011). It is in this regard that the concept of 'vulnerability' to environmental migration, as conceptualized by Wisner et al. (2004), is helpful. This concept acknowledges the role humans play in the production of environmental hazards and their uneven dispersion. Vulnerability captures the chronic insecurity and exposure to risk, putting the unequal distribution of power and risk across the population at the heart of the analyses. Using vulnerability as a concept helps comprehend the complex relationship between migration and environmental changes that heavily depends on the prevailing types of environmental change, the surrounding socioeconomic and political contexts, and the types of human mobility trajectories (TGOFS 2011; Piguet et al. 2011; Schilling et al. 2012). 


\subsection{Cultures of Migration}

The impact of both environmental change and migration expands over many decades. Therefore, it is important not only to focus on the longitudinal impact of environmental change on people living in a particular area, but also to consider the cumulative effects of migration (Stark and Bloom 1985; Stark 2005; Myrdal 1957). The introduction of the notion of 'culture of migration' is therefore necessary to understand the development of migration aspirations and considers local and transnational networks that further shape the ability to migrate. Migration - especially transnational migration - could be made easier in regions with a prevailing culture of migration which stimulates additional migration or limit migration aspirations, as feedback mechanisms have already shown that migration can lead to lower social positions in the immigration country, jeopardizing the opportunities to send remittances (De Haas 2006; Gemenne and Blocher 2016; Simon 2018; Timmerman et al. 2014). The combined study of 'culture of migration' and 'environmental migration' is innovative for two reasons. First, the availability of migrant networks and particular cultures of migration impacts the opportunities to - individually or collectively deal with the consequences of environmental change through remittances and/or specialized knowledge, expertise, and political power also affecting migration aspirations (e.g. De Haas 2006; Carling and Hoelscher 2013; Gemenne and Blocher 2016; Obokata and Veronis 2018). Second, both migration aspirations and environmental discourses are either fuelled or hampered by a particular culture of migration, blurring or strengthening the relationship between the consequences of environmental changes and migration aspirations. Migration is frequently used to diversify family income sources, regardless of the confrontation with disruptive environmental changes (TGOFS 2011; Gemenne and Blocher 2016; Carling 2014; Kusunose and Rignall 2018).

\subsection{Results}

\subsubsection{The Development of Distinct Cultures of Migration}

As the results of Chaps. 5 and 6 have shown, respondents' views on the perceived environmental changes in their immediate living environment vary across and within regions, depending on sociodemographic features. This finding is helpful for understanding the development of migration aspirations induced by environmental change and the distinct vulnerabilities towards them, resulting in distinct needs and aspirations to migrate. Both regions have faced extensive emigration, and almost everyone knew someone living abroad or who migrated earlier. This was clearly noticeable when simply walking around in Tangier and Tinghir: everyone had heard of Belgium. More strikingly, many people immediately responded that they knew someone who went there, had (distant) relatives there, or knew that a lot of people 
had migrated from Morocco to Belgium (and other European countries). Some words like 'goedendag' (have a good day) or 'dank je wel' (thank you) were already shouted at me when passing by (again) on my daily routines towards the place where I stayed. First impressions were that in Tangier, street vendors in the neighbourhood where I lived immediately told me that 'they were better than the ones in Belgium', repeating that Moroccans in Belgium were lazy, did not work, and that I should distinguish them from the 'hard working Moroccans' like themselves. By contrast, in Tinghir, people rather stressed how many people they had known who had moved to Europe, but that they themselves were not willing to move, as they did not like 'the stress in Europe' or could not 'bear with the cold' to justify or claim that their stay in Morocco was positive. Others rather searched for marriage or work opportunities and promptly personally asked me for more information on both. I interpreted the recurring discourses told on the streets during my daily walk as clear signs of the existence of well-established cultures of migration. In Tinghir, this culture of migration was also visible when walking in the city centre and observing old men sipping mint tea, all spending their retirement years between Europe and Morocco. Hence, in line with migrant networks theory, I asked more profound questions on these cultures of migration during the interviews.

The first interviews already showed that nowadays, migrant networks are not equally accessible for people coming from the lowest social classes, which are also the most vulnerable to the consequences of environmental change. In Tinghir, especially, nomads and very poor families - in contrast to their surrounding social environment - hardly had any contact person or family member who had migrated outside Morocco. To make sense of the data and to understand how seemingly similar natural phenomena are perceived differently, the consequences of high emigration over the years are explicitly considered during analyses in order to understand local structures and corresponding views. Tangier and Tinghir are mainly characterized by two different cultures of migration with distinct economic profiles. Whereas in Tangier migration is already perceived by people from higher or middle classes from a more critical perspective, the positive sides of migration are mainly stressed by respondents living in Tinghir and less socially-advantaged people or recently arrived migrants living in Tangier (i.e. internal migrants who migrated for better opportunities to larger cities). These diverging cultures of migration, between and within regions, seem to be related to 1) the discourses heard by their relatives/ migrant networks; 2) the relative position people occupy in Moroccan society and in a particular region; and, 3) the reliance on migrant remittances and access to transnational migrant networks. I first discuss the prevailing cultures of migration for each region separately.

\subsubsection{Regional Differences: Tangier}

As Tangier is a vibrant, harbour city, with numerous international networks and companies as well as internal migrants, migration is a part of everyday life. On the 
streets, some inhabitants wished to distinguish themselves from the 'lazy Moroccans in Brussels who do not work', by stating 'we work here, we like to work'. They promoted the good values of Moroccan life, such as working hard, and by doing so, cast themselves in a positive light. The immediate impact of migration is less clearly visible for everyday life, as it is obscured by the large diversity of professions, city life, international companies, and the investments of the Moroccan King and government. Greater variation in education levels and livelihood strategies made people rely to a lesser extent on remittances from Belgium (or other European countries) and turned the impact of migration into an individual or structural question.

Migrant networks provide support by channelling individual remittances during religious holidays or festivities, by supporting the ability of their relatives' children to attend private schools, or by contributing to healthcare costs. On a more structural level, associations and companies are set up with support from migrant networks and European governments. Many inhabitants have a personal (intergenerational) migration history that ended in Tangier. This is for instance the case for Hasna and Sarah (33 and 38 years old), two sisters whose family migrated to Tangier when they were respectively 13 and 18 years old:

Sarah: The reason we came here was that, before the death of my father, he decided to come and live here as there was nothing to do in the small village where we lived. There was no big company, it was more or less an agricultural village, the agricultural life. He migrated to give us a better future. That's why he decided to come to Tangier. (...)

Interviewer: Do you want to stay in Tangier or migrate later elsewhere?

Sarah: Another city in Morocco?

Interviewer: It doesn't matter where to?

Sarah: No, well I have never thought of migrating outside Morocco. Only when I visit for example my sister or my brother yes, but to really live there? No, I couldn't, I have a lot. . I I love to live in Morocco, and I even don't want to change from the city either. It's without a doubt that I adore Tangier (laughs).

Hansa: That's for sure

Interviewer: What are the things you like about Tangier?

Sarah: A lot of things here in Tangier, the seaside, the quietness, there is a big city, it's superbe.

Hansa: It's beautiful, it's magnificent.

Sarah: If we would return to the South, that's also super, but to live, for me, not really, I only want to go on holidays there, that's it! (...) there is no nature, it's an industrial city, there are many companies here, it's the economic capital from Morocco.

When Sarah and Hansa later mentioned having some family in Europe, they explained that some of them had returned from abroad due to economic reasons:

Sarah: I think the majority of the people who travel across borders, migrate to work, to improve their material capital, to find work. For sure, Europe is more civilized than Morocco, but they don't always respond to the needs of the migrants. People find work here in Morocco, as you have to work. I personally have a brother who travelled to Spain, he 
stayed there for I don't know how much time, and then he returned to Morocco. He returned after about 10 years, due to the [economic] crisis.

Interviewer: Are there a lot of people who return?

Hasna: Ah ouiii

Sarah: Especially from Spain, there are many, but even from Belgium. There is nothing there, they left for Spain for work, but they couldn't find work.

This interview extract shows that many people do not automatically perceive migration as equated with success because people can be very vulnerable in European labour markets - especially due to the recent economic crisis. Furthermore, when people return to Morocco, they are more likely to return to larger cities again, to improve their chances on the labour market - which increases the visibility of return migrants for people living in Tangier. When comparing life in Europe with life in Morocco, many people stressed the differences in lifestyles, the nicer atmosphere in Morocco, and the 'failed integration in Europe of many immigrants'. For instance, Faiza (female return migrant from Belgium/France, 28 years old), who now works in a large international company located in Tangier, recalls experiences of discrimination on the tram and certainly does not think of returning, stating:

Interviewer: Are you planning to migrate another time in your life?

Faiza: I am good here, one year and a half, I asked my husband whether he wanted to return to Belgium, and he said no. He told me that he felt good here, and did not want to return. Even when we go there for a week, we don't understand the people. The majority goes to a psychologist or a psychiatrist. Here, we are our own psychologists. If I have a problem, I call a friend, I tell her everything, she comforts me and gives me advice. In Europe, people don't even have time for themselves, how can you make time for someone else?

This account shows that Faiza clearly appreciates Morocco more (after she left to enrol in higher education in Europe), and cherishes Moroccan culture. Ali (male, 65 years old) similarly mentioned the presence of a warm climate in Morocco and felt quite hostile towards Moroccans who had migrated to Belgium and France, despite having served a ten-year prison sentence in Morocco for expressing his political opinion and having a lot of family living in Belgium and France. At the time of the interview, he had just sent his daughter - who had been unemployed for a long time in Tangier despite her higher education - to his family in Belgium without a residence permit. Nevertheless, he remained sceptical about the integration of Moroccan immigrants in European societies, such as Belgium and France. He argued that the migration project had failed as many Moroccan migrants continued to hold on to their own laws, contradicting the ones of the immigration country. He referred to the lack of recycling ('Why don't they use the correct colours of garbage bags?') or the fact that most migrants lived in ghettos such as Schaarbeek and Molenbeek in Brussels. A third example he gave touched upon the education of children, for which he felt that migrants placed their own punishments above the ones of the government. He narrated the story of a man whose son used drugs and behaved badly in Dutch society. The first time, he beat his son; the son turned him in and he had to go to jail. The second time, the son wrecked a stop sign, so the man 
turned his son in to the police as he could not beat his son again. A third time, the father brought his son back to Morocco and took away his passport. As the Dutch authorities realized the son did not return, they searched for him, returned him, and put the father back in jail. According to Ali, these examples show how difficult the integration of Moroccan immigrants have been over the last decades.

These accounts illustrate how many Moroccans, who report being satisfied with their lives in their country, do not even contemplate migrating to Europe. The cold and unsupportive atmosphere, distorted work-life balance, higher stress levels, the 'bad climate' (i.e. a lot of rain and not so much sun, cf. Chap. 5), integration difficulties, and enduring experiences of discrimination, do not lead them to search for ways to migrate. For this group of respondents, migration was rather seen as something from the past, as Morocco - and especially Tangier - is experiencing an economic revival and a recent rise in investments in the region. Furthermore, the idea that European borders are increasingly closed and that it has become harder 'to get in' is also prevalent, causing people to rethink and reframe their migration aspirations. In other words, if one is happy in Tangier or Morocco, why even bother going to Europe and putting so much effort in it? Many people who were satisfied with their lives or jobs or both, did not consider migrating to Europe. This seemed particularly true for people with a (relatively) higher educational level, people with social and family networks in Tangier or those who had grown up in Tangier. 'Real Tangériens' have the reputation of enjoying life and adapting their life rhythm to the harbour schedules, starting late and working late. The existing inequalities in Moroccan society, which are particularly visible in cities like Tangier, are also reflected in the ideas about migrating to Europe. While the overall perception in Tangier is that migration is a 'failed project', this is not necessarily reflected in the aspirations of those who are unemployed or experience harsh working conditions in Morocco.

When looking at all the accounts of the respondents living in Tangier, a divide is clearly noted between people who were from Tangier or who had built up a good life there and recent internal migrants who had come to Tangier as part of their fragmented journey or in search of better opportunities. This is, for example, clearly the case for Imane (female, 35 years old, coming from Oujda) and Amine (male, 28 years old, coming from Al Hoceima), who had both migrated in search of better legal and economic opportunities, and were 'on their way to Europe'. Amine did not foresee any job opportunities in Al Hoceima, was already married to a Belgian woman of Moroccan descent but had not been able to migrate yet. He was forced to interrupt his studies to obtaining his high school diploma when he had take care of his parents after his father got sick. While initially, his main migration aspirations were linked to his love life, he described very difficult conditions in Al Hoceima, adding that he did not want to return (see also Chap. 5):

Interviewer: A lot has changed during the last years in Al Hoceima?

Amine: Life is difficult now, a lot of [imitates gunshots] the police check people a lot, they enter your house, you cannot eat, you cannot enter the hospital, even when people have 
cancer. They enter your house and then blablabla and then taktaktaktak and then everyone have to go to the police station, chained.

Interviewer: In your family?

Amine: No, not my family, but friends. Al Hoceima is a beautiful city.

Interviewer: Do you want to return?

Amine: To Al Hoceima? No, totally not! Jamais! My family came to Tangier, they don't want to go back to Nador. [starts crying]

Later in the interview he also described the problems they had encountered with the dam in Al Hoceima, which the government built in just a month to solve water issues. Unfortunately, the dam had burst, flooding or damaging many houses in $\mathrm{Al}$ Hoceima. According to Amine, instead of helping the inhabitants, 'they' [the police] killed people. The work was conducted by Portuguese labourers, and therefore did not contribute to the employment of local workers. As all these problems resulted in a lack of job opportunities, Amine referred to 'work' as the main driver for migration. At the time of the interview, he worked in a shop in Tangier, owned by his wife's grandmother and was awaiting a visa to go to Belgium.

Similarly, Imane, a single mom who suffered from a lack of social acceptance linked to her divorce and abuse by previous employers, was in constant need of money to provide for her daughter and her daughter's future. Imane's child was temporarily staying with Imane's sister and Imane was now working as a maid, under sometimes very harsh conditions. She deemed this life necessary to find a way to go to Europe, and therefore also to a great extent did not enjoy living in Tangier. She missed her daughter, lived in a small room, and worked hard. Having no access to migrants' discourses she had no way of knowing that life in Europe would not necessarily be better than the life she was living now. She mentioned the lack of economic opportunities and political conflicts that make it very difficult for unqualified youth to find a job in her region of origin. Indeed, in that region, people have long been confronted with water scarcity and drought.

Interviewer: In Oujda, are there a lot of environmental problems, such as water scarcity or drought?

Imane: No, it's normal there

Interviewer: You know a lot of people who work in agriculture?

Imane: In Oujda? Yes, a long time ago, young people in Oujda worked well. You know what they did? They worked together with Algeria, you know what, it's always the same, only the young people from Algeria and Oujda used to work, but now they can't. It's already been a year since they have stopped working together with Algeria, there are a lot of problems now and the borders are closed tight. They have problems with the King [Sic] of Algeria, but the young people stay without work. I am talking about the people who did not finish school and have no work now. Oujda is a small village where there is not a lot of stuff to do, the only thing used to be working in Algeria.

Interviewer: And what do the youngsters do right now?

Imane: Sometimes, they sell stuff, but they act like they are thieves, because they need money. Youngsters from 18 and 19 years old, who don't have a job, become thieves and 
steal. It's a real problem, that's the biggest problem in Oujda, to provide work for people. It's not like Tangier, where there is a lot of work for young people, to buy clothes, and a lot of stuff, but not in Oujda.

Both stories refer to the lack of decent working conditions and supportive political environment in the interviewees' regions of origin. This situation made them more determined to migrate to Tangier and think of alternatives to secure their livelihoods. Both respondents had limited social networks in Tangier on which they heavily relied and depended upon for job opportunities. To them, Europe appeared like a promising option that would always be better than staying in Morocco. Amine's and Imane's poor socio-economic conditions and status made it difficult to be certain whether they would be able to realize their dreams, as shown by Imane's interview extract:

Imane: Especially this year, we had a crisis in Oujda

Interviewer: A political crisis?

Imane: Above all, people don't want to stay in Oujda anymore, everyone there, they do all things possible to return to France or Spain

Interviewer: And you would also like to go to Spain or Europe?

Imane: Me, I would like to go to Spain.

Interviewer: Yes?

Imane: Yes, (laughs) I would like that. It's been a while since I married [name] in Spain, but it's a marriage blanc [marriage without consumption]. That's why I always said: if possible I would like to go to Spain.

Interviewer: You think it's easier to go since you are already in Tangier?

Imane: Of course! I think like that, for me, if I would work with someone good, who would give all papers and a good salary. That's why I am here, voilà! Now, I work at the place of a rich lady, I am very lucky. I thought: 'Why not?' If there is a small chance, I would like to return to Spain, but I don't know how, that's the problem. It's not even only for me, sometimes I think: 'It's me or my daughter'. I would do everything so she could go as well and she could continue school, and so she might even become a doctor or a professor.

Although Imane's account shows that she had already undertaken some actions to achieve her dream, namely (temporarily) moving to Tangier, it remained unclear whether she would be able to really migrate to Spain.

To conclude, in Tangier, the social inequalities within Morocco seem to be reflected in the development of cultures of migration, not only across regions/ cities/villages, but also across social classes. This finding builds further on insights in social networks research, indicating that social networks within Tangier are also very socially homogeneous (e.g., McPherson et al. 2001). These socially layered networks then shape distinct cultures of migration. The more socially advantaged groups often have more extensive networks and relatives in Europe and can thus already benefit from some kinds of remittances, support, and network in times of hardship. Yet, this group is also more aware of all the disadvantages related to migration, such as experiences of discrimination and 'ghettos', which results in a 
critical stance towards migration to Europe. The more socially disadvantaged groups, who often have internally migrated from regions experiencing economic and political insecure or instability, have less access to migrant groups. Therefore, they are less able to put their migration aspirations into practice (due to a lack of financial means and migrant networks), but also have less information that could distort or nuance the positive image they have of migration to Europe. Thus, the ability to migrate as well as the frames of comparison vary across both groups. These differences also contribute to the creation of distinct cultures of migration within Tangier itself.

\subsubsection{Regional Differences: Tinghir}

The result of the longstanding tradition of migrating to Europe since labour migration started after World War II has a clear impact on the existing cultures of migration in the city of Tinghir. Here, you see large quarters of concrete houses next to neighbourhoods of (sometimes desolated) traditional homes made of clay, which are slowly but surely deteriorating - literally falling into pieces. After the first migration flows to Europe that followed the second world war, migrants regularly returned to their families in Tinghir during holidays and started to build concrete houses similar those they had seen in Europe. These houses have a lot of modern advantages but could not always compete with the traditional houses in terms of natural insulation, heating, and cooling. Nowadays, many of the traditional houses are still (partly) in use, especially during the cold winter months as they provide better protection against the cold. This juxtaposition of concrete and traditional houses is very characteristic and demonstrative of migration's impact on Tinghir, and clearly enables to distinguish people with migrant networks from those without. In the city centre, streets are filled with Moroccan tea shops, as well as with returned retired immigrants and people living off the money sent by their relatives. The undeniable impact of migration on the city shapes social life in countless ways. The city breathes migration, and this has univocally led to the creation of an unstoppable culture of migration sustained through continuous chain migration.

This ongoing culture of migration can partly be ascribed to the current socioeconomic situation of Tinghir. The city suffers from decreasing agricultural output (and investments) and struggles to offer sufficient (decent) working opportunities to its inhabitants. Hence, given the far-reaching impact of migration on everyday life and the local economy, it is very understandable that migration is still perceived in a positive light by most respondents. Leaving aside whether migration contributed to Tinghir's development over the years, the inhabitants mainly looked at it from a personal perspective or in a positive way, or both. The fact that most migrants approached migration this way is especially related to the assets and resources migration has brought for the respondents' relatives and the increase in employment opportunities for migrants themselves. Hardly any differences were found across respondents with regard to their (positive) image of Europe. Respondents referred to 
Europe as a place where people have to work hard, deal with a lot of stress, and where there are still some opportunities to work, especially for young people. Nevertheless, the combined effects of the European economic crisis, changes in European immigration laws, and of the end of organized labour migration in Europe have resulted in fewer opportunities to migrate, regardless of one's family networks or resources. As mentioned by Zahib (female, 33 years old):

Zahib: It's difficult [to go to Europe] and it's also not so difficult. It's possible to go as a tourist, but not when you search for a contract to work there. There are many young people, who go to France to work but who do not find a job... it's the global crisis, it's really not like in the old days, even people in France encountered difficulties due to the crisis, especially in Spain I guess.

Prevailing cultures of migration do not really help to explain differences and changes in environmental migration aspirations, but matter because of the creation of transnational social capital (see also Portes et al. 2002; Eckstein 2010). Given the extent of emigration out of Tinghir, inequalities have developed over generations between those who have and those who do not have access to transnational immigrant networks. However, even in such a major (transnational) emigration area, some households still report not having contacts overseas or linkages with families who do. Views on environmental change in people's immediate living environment differed according to respondents' transnational social capital (see also Portes et al. 2002; Eckstein 2010), which is also a crucial condition for the development of migration aspirations due to environmental change.

Building further on the results shown in the previous two chapters, differences in perceived environmental change in people's immediate living environment are mirrored in structural differences in society, and reflect differences in the living standards, education levels, and professional activities. The latter factors are very visible in everyday life and are crucial to understand emerging patterns in perceived environmental change. They also reflect the resources people receive from their migrant networks. Having transnational immigrant networks provides a type of social capital that matters for the development of environmental migration aspiration for two main reasons: (1) the sharing of knowledge about environmental/climate change discourses in general (e.g. through education or media) and in their living environment (e.g. through education or tacit knowledge and skills) (cf. Chapters 5 and 6); and, (2) the necessity to work in a subsistence economy (due to a lack of alternatives or education) and, hence, the lived experience of environmental change in daily life. Both reasons are partly related to the transnational social capital that seems to structure inhabitants' perceptions of environmental changes in Tinghir and its environs.

In the following sections, I discuss the migration aspirations of these two groups those with and those without local and transnational social capital - separately and discuss the ways in which these potential aspirations relate to environmental changes. I also set out how transnational social capital results in distinct vulnerabilities towards environmental changes and distinct possibilities and imaginaries with 
regards to migration. Social, economic, and educational inequalities were fuelled by the receipt of remittances and consequently enlarged over the years.

\subsubsection{Transnational Social Capital Reduces the Need for (Environmental) Migration}

This section mainly applies to respondents living in Tinghir since they face more environmental changes in their immediate living environment and for their work activities. For families with transnational social capital, such capital appeared crucial for the development of environmental migration aspirations in two ways: through remittances that stimulate and make education, entrepreneurship, and investment in associations possible, and through knowledge transfers about environmental change (in terms of teaching and discussing climate change discourses, cf. learning method of environmental change). While the first reason may make environmental migration aspirations seem superfluous, the second could provide the grounds for solidarity with more vulnerable groups in society with regard to environmental change, and thus serve as an incentive to set up an association that could serve as an adaptation strategy to deal with environmental change.

Remittances were mainly destined for the respondents' individual use, generally improving the education level within their families and making them more prone to invest in local businesses (regardless whether these businesses were economically viable or not). It also improved their ability to migrate to larger cities (e.g. Casablanca or Tangier) to look for work. Hence, people receiving such financial remittances opted to move away from working in a subsistence economy. Ironically, this same group is the one with greater access to agricultural fields. As also shown in a study from De Haas (2006), there is a higher percentage of people without land among non-migrant and internal migrant households, compared to international and returned migrant households living in Tinghir. As illustrated by the case of Zahib (female, 33 years old, Tinghir), (higher educated) young people especially no longer wish to engage in this subsistence economy:

Zahib: We do not encounter problems, only in Zagora, where the desert is expanding. Here, in Tinghir, people are left to work in agriculture. A lot of people used to work in the forest but nowadays, only a few do so, people have stopped working in agriculture.

Interviewer: How come?

Zahib: Because people don't wish to stay here, working in agriculture, they rather go to France, and Europe. Most young people living in Tinghir, migrated to Europe, because here, there are no means to work, there are no factories, there are no places to work. So, everyone has 'the mentality' to go and migrate, and that's why they have left it [agriculture]. For the older people, life goes on, they are tired, they have grown older. I think that when they will have built the dam, people will return, because now when it rains, the river just mixes everything together, causing a lot of problems afterwards. Because if people work on their fields, and later, the river takes it all.... when the dam is constructed, all these problems will cease, as we have a good climate and clay... The ground is of good quality, after they have 
built the dam, people will return, in order to set up modern projects, and improve agriculture here. I think that, because people would like to work. But now, the river always causes too many problems when it rains a lot.

According to Zahib, high emigration rates result in changes in land ownership and in the attractiveness of investments in subsistence agriculture. This is not necessarily only due to environmental changes but should be placed in its context of rising standards of living. The combined effects of rising standards of living and cash inflows from remittances often discourage young men to 'get their hands dirty' and work - leaving the 'old' economy behind (see also Kusunose and Rignall 2018) and aspiring to participate in the 'new' economy, without necessarily being able to do so. These societal changes have a variety of consequences, gradually reshaping family life, agricultural work, and food prices. This is for example the case for Muhammed (male, 60 years old, guardian of a classified mosque, Tinghir), who stated that 'everything has changed'. In the early days, he said, parents arranged everything for their children's marriages and even gave a sheep and a clog of silver as dowry to the bride's family. Nowadays, young people are allowed to choose their partner themselves, which is not as easy as it seems, as he explains. As he argues, men do nothing and thus cannot afford to marry anymore. Although his five daughters are all ready to marry, and over 18 , none are as they cannot find a man who can afford marriage. He argues that studying could improve the chances of finding a good husband. Others, like Houda (51 years, female, Tinghir), only reported experiencing the impact of environmental changes through the rising prices of vegetables and meat. This group is overall more educated or wealthier or both, which opens the possibilities to work in administration, education, or in local businesses and thus reduces the need to work in agriculture, especially in subsistence farming. Consequently, when this group is confronted with environmental changes within their immediate environment, there is less need for adaptation because of their personal use of remittances to mitigate such shocks.

Although people with transnational social capital are more highly educated and have more theoretical knowledge about climate change discourses or environmental changes from a scientific perspective, these ideas are less easily converted into their own immediate living environment; these people (and youth in particular) are better educated but less aware of the implications of such changes for agriculture. Those with awareness are often informed by their transnational networks and make use of their remittances and networks in a collective way to set up associations. These associations do not aim to counteract the consequences of environmental changes or mitigate them, but rather strive to prevent (environmental) migration. They do so by providing new employment opportunities and modernizing traditional agricultural techniques, circumventing traditional laws and customs in the process. This is for example the case for Younes (male, 40 years old). Younes frequently visited Belgium and had many local contacts (of Belgian background) there. He was the president of an association whose activities aimed at transporting school girls to increase alphabetization; reconstructing and repairing water canals to irrigate the fields; installing solar panels to dig up water and irrigate the immediate surroundings 
of a school; providing internships for midwives; and breeding a particular stock of goats that gives more milk. He said that his views on migration had dramatically changed, and that only the poorest wanted to go to Europe, which they perceive as 'heaven' ('Le paradis'). He was often attempted to persuade young people to abandon their European dreams and focus on Morocco instead. For instance, he stated that one cannot survive without having a job and that society's focus including in Morocco - is directed at material goods (such as possessing a car) instead of the collective good. As an alternative, he suggested investing the money sent by relatives from abroad to start an enterprise in Tinghir. Having said that, Yunes regularly goes back to Belgium for several months at a time and only returns periodically to Morocco to continue working for his association. This practice of setting up associations at a grassroots level to compensate for the lack of a wellorganised social welfare system in Morocco is very common in the Moroccan context. Policymaking is very strongly developed at the national level but does not include many initiatives oriented at the meso-level. This results in an abundance of small, uncoordinated, grassroots-level initiatives that are sometimes supported by local authorities or associations abroad. It is exactly through this practice of setting of associations that often only involve a couple of persons that migrant networks or transferred knowledge make a difference and could turn migration into a successful adaptation strategy for dealing with environmental changes (cf. Steinbacher 2015; Isaakyan and Triandafyllidou 2017).

\subsubsection{Increased Vulnerability to Environmental Change, without any Migration Opportunities}

People living in Tinghir without transnational social capital suffer from relative deprivation compared to their neighbours. The lack of such capital is mainly visible through the lack of remittances, thus relatively lower financial resources. Therefore, these families muts compete with businesses that survived on remittances and are not necessarily being financially viable. Furthermore, they have no safety net in case of hardship (as the government does not adequately provide social security and services). For instance, if people need to visit a hospital that offers more than basic services (like the hospital in Tinghir), they need money and time to travel to Marrakech. This unequal distribution of social safety nets is further reinforced by the fact that the lack of transnational social capital frequently coincides with a lack of local immigrant networks (e.g. in larger cities in Morocco). Hence, these families more often lived in 'traditional' (i.e. clay) houses, usually lived in poverty, and displayed lower educational attainment levels. This was, for example, the case with one of the interviewees' sons who did not have any transnational networks: when asked by his father to quit school in order to help to contribute to the family's income, he went to Libya for a year, without knowing that he would be unable to send money back to his family; later he had to flee because of political turmoil 
following Muammar Gaddafi's death. Living in a region that has experienced a lot of emigration does not immediately contribute to a general increase in people's living standards, as remittances are mainly used individually. This contrasts with the case of Houda (female, 51 years) who was able to stay with her in-laws in Marrakech when her husband got ill in order to be closer to the hospital.

Due to overall difficulties for survival, and especially to relative deprivation compared to larger groups of people having access to transnational social capital, these families are more likely to depend on agricultural work, which increases their vulnerability to environmental changes. More specifically, women continue their work in the fields; their harvests are not meant to be sold on the market but for their own use or for feeding their animals. An example is Rachid (male, 56 years old, kiosk seller and agricultural president of local NGO, Tinghir). He recognized that only women were still working in the fields as this type of outdated farm work is not sufficient to provide for a family; he did not link this inadequacy to to environmental changes but rather to the organization of local agriculture.

Rachid: Nowadays, it's only for women, because we are obliged to abandon agriculture. We really said that we need a solution for agriculture, because we only have a small parcel, and another one, and you can work on it maybe for a day, two days maximum, but without providing you the essential income to provide for you and your family. It's just not possible, it's impossible. We leave it [agriculture] aside and we plant alfalfa and a couple of things, but it's only to pass the time. It's really insufficient.

This extract demonstrates that environmental changes create the conditions in which migration imaginaries may be developed. Migration may seem like a perfect escape compared to other adaptation strategies since environmental changes are not being dealt with in a structural and updated manner and are linked to particular land use and governance. The linkage with environmental factors is not being made here, but occasionally arises when discussing agricultural decline. This extract illustrates that it is mainly people who lack other means who continue to put effort in agriculture.

While large groups of people (mainly men) leave agriculture as their main profession, poor people living in the surroundings of Tinghir (including nomads) migrate locally towards Tinghir to borrow land and work on the field, which is illustrative of the survival difficulties of people living in surrounding areas. Therefore, when people tend to leave their fields in order to take the easiest and safest way out, there remains a group of people living in poverty and who still rely on agriculture or who would see agricultural work as an improvement of their situation. This is illustrated by the story of Rehana (female, 46 years old, interviewed through a male interpreter), who grew up in the Tinghir area and who, before marrying, contributed to the family income by collecting wood in the mountains for heat and cooking. Now that she is married, she wishes to own some agricultural parcels or cattle or both, in order to contribute as well to the household income:

Interpreter: She would love to go to the field, she adores it, but she does not have money because her husband is poor. He doesn't have fields, he doesn't have animals. If she would have had animals and fields, she would have gone for sure. If there would be someone who would buy a cow, she would ask - even if she doesn't have the space to keep the cow - she 
would ask whether she could take care of it. But as she doesn't have any means, she stays at home.

Interviewer: Why would she like to do that?

Interpreter: She said that, for them, like I said earlier, animals and fields, are ways to animate the households' income, as her idea is to help her husband. She knows very well he is poor, and she wants to help her husband. If her husband were rich, she wouldn't bother and she would only focus on the air-conditioner, painting the house, etc.

The complex interlinkage of environmental, gender, social, cultural, economic, and legal factors creates vulnerability towards environmental change, without necessarily giving rise to well-developed migration aspirations. Given the poor living conditions, migration is not considered a valid option for those who suffered the most from environmental change - namely elder women - and are rather passed on to their children, as was also the case for Chaima (female 55 years old, Tinghir), who was interviewed, accompanied by a male interpreter:

Interviewer: Would she like to move to Europe?

Interpreter: Non, this family, non, nobody. Everyone works here, they work on their ground here. They work on the fields, or they work in construction. They all have their reasons for this, they cannot leave Tinghir, they have to stay here in Tinghir.

Interviewer: But, would she like to move, alone or together with her family to Europe?

Interpreter: I don't think it's possible, wait, I will tell her (they talk and laugh very hard). That's a good one! She says that she would like to leave and migrate to Europe under the condition that you take care of her children. She said that you have to watch her kids (laughing). You should stay at her place and then she takes your place (laughing).

Interviewer: Would she like her children to migrate?

Interpreter: She said yes! She said that if her son finds a place to work in Europe, she agrees! What can he do here?

Hence, the most vulnerable group to environmental change would consist of those working in agriculture, lacking financial resources, and who have reached a certain age, which makes it impossible to even imagine migrating as an option. This group could be seen as a 'trapped' or 'immobile' population' (Zickgraf 2018). And more in particular, this form of immobility can be described as 'acquiescent immobility', referring to those who do not wish to migrate and are unable to do so (Schewel 2019). As their children decide to not contribute to the work in the fields and migrate due to the lack of employment opportunities, it is hard for them to make the connection between their migration aspirations and environmental changes. This means that hardly anyone develops migration aspirations and links these aspirations to environmental change. This is especially visible when looking at the interviews with younger respondents. Similar responses were given, all referring to 'what they can do here: nothing', like Zohra (female, 24 years old): 
Interviewer: Last time you already told me you would like to go to America.

Zohra: Yes, that's my dream, I wish to get there one day, I want to live better than now, I want to get a job, and then live how I want, to have my house, to do what I want, here it is difficult to do what I am seeing.

Interviewer: What do you mean with: it is difficult to do what you want to do?

Zohra: It is difficult to get a job, a good job I mean, it's like...here, girls don't get jobs, it's a little bit bad, I can see. That's why.

Interviewer: What would be a good job for you?

Zohra: I don't know yet, because I don't know what jobs there are in America, but I can do any job!

The lack of employment opportunities as a reason to migrate is widely shared across all groups:

Nayla (female, 45 years old): There are many people here that migrate towards Europe and also in Morocco, because there aren't that many employment opportunities. There are no factories, no enterprises, there is nothing, even if you want to invest money in larger projects, you are not able to do that here. You are almost obliged to move to bigger cities.

Interviewer: Why not?

Nayla: Because there isn't a big infrastructure. People cannot afford to buy things, you cannot do a lot of things here. It really depends on their capacities.

The results of this study force scholars to reconsider vulnerabilities to environmental change and include an intergenerational element. This is particularly true in regions where environmental changes gradually change over generations. As a consequence, environmental migration can hardly be observed at the micro-level, for example measured through migration aspirations or actual migration, but is a concept that seems to be only linked at the meso- or macro-level.

\subsection{Conclusions}

Findings from this chapter demonstrate that by examining environmental migration aspirations, existing shared conceptions on how environmental change could be linked to migration are challenged. Insights and concepts from migration theories, such as the migration systems theory (i.e., 'cumulative causation', Myrdal 1957; and 'culture of migration', Timmerman et al. 2014) as well as disaster studies (Faas 2016), help to understand how people's vulnerabilities and resilience to environmental changes in combination with differentiated abilities to migrate result in or hamper the development of - sometimes intergenerational - migration aspirations. This study demonstrates empirically how perceived environmental changes, agricultural practices, socio-economic developments, and cultures of migration are relevant for understanding the adaptation strategies that people affected by gradual degradation of the environment use or aspire to use (see also Schilling et al. 2012). We summarize the findings of this study briefly. 
First, this chapter shows that the history and patterns of migration from Morocco have led to the creation of three different cultures of migration: two within Tangier and one that in general prevails in Tinghir. More socially advantaged groups (both in Tangier and Tinghir) are often part of a culture of migration in which information obtained through transnational networks have resulted in less urgent or expressed migration aspirations. Through dynamics of negative cumulative causation (cf. Myrdal 1957), these people - who occupy a relatively good position in Moroccan society - have received ample negative feedback, which undermines their motivation to migrate and makes them cherish their life in Morocco even more. Those who are less socially advantaged are less well-informed about life in Europe and mainly see more advantages related to migration, perceiving the outcomes of migration positively. They see the impact of financial remittances sent back to relatives, which is for instance clearly visible in the construction of houses. Additionally, they also more easily note the opportunities to find jobs, receive support to enrol in education, or search potential marriage candidates abroad. This divide takes different shapes in Tinghir and Tangier, and can partly explain regional differences found with regards to cultures of migration. This is understandable since these settings differ with regard to social inequalities, visibility of the impact of transnational migrant networks, job and educational opportunities, and migration dynamics. As a consequence, social remittances such as knowledge transfer concerning scientific climate change discourses, ideas on the development of adaptation strategies, and financial or material support for local associations in Morocco and creating work opportunities, are being sent and shared in these local communities in Morocco. These social remittances can contribute to solidarity within the local community or within social networks within the same municipality (Levitt 1998). Finally, these distinct cultures of migration, impacting social structures in Moroccan society to a high extent, actively shape migration aspirations and the ability to realise these aspirations. For example, when looking at the importance of the culture of migration in Tinghir (De Haas 2006; Carling and Hoelscher 2013; Gemenne and Blocher 2016; Obokata and Veronis 2018), migration is still regarded in a positive way for most inhabitants, however, not all of them are able to translate this positive view into actual migration aspirations. This brings us to the another main conclusion of this chapter.

Second, findings indicate the creation of parallel groups that differ with regard to environmental migration aspirations and vulnerabilities and resilience towards environmental change. These social inequalities are created and reinforced due to differences in transnational social capital (Portes et al. 2002; Eckstein 2010). As some initiatives are organized to prevent young people from migrating by offering improved and valid opportunities in agriculture in Tinghir, migration aspirations themselves are hardly linked to environmental changes at the individual level. The connection between environmental change and migration appears to have been lost across generations. This is particularly true for those without transnational social capital as they are more vulnerable to environmental changes, due to the lack of remittances and an increased focus on agricultural activities as a way to complement the family income. Understanding the situation of these families - where it is 
predominantly women who are confronted with environmental change as men search for alternative employment opportunities - could give a more nuanced substance to the definition of 'trapped populations' (Zickgraf 2018). Hence, the most vulnerable group affected by environmental change - elder women - does not even dare to put their dreams into actual aspirations or practice. Instead, they wish their children would migrate for better employment opportunities and hence, diversify household incomes and spread risks (cf. new economics of labour migration). As the next generation is not even familiar with environmental change, they also do not connect their migration aspirations to changes in their natural environment, but rather refer in general to the genuine lack of all kinds of opportunities. Thus, in line with Crawford (2008), migration aspirations are not necessarily turned into migration decisions, which should be understood within the socio-economic context and the social organizations of the households in which people live. These findings urge scholars to rethink the existing categories of ideas concerning environmental migration and transcend the individual level. In line with the new economics of labour migration, migration should be seen as a project of households. Hence, when searching for ways to better protect people affected by gradual degradation of their natural environment and streamline environmental migration, scholars and policymakers should focus on entire households or extended families instead of merely looking at individuals. In this sense, the resilience and vulnerabilities of the elderly with regard to environmental change should be inquired about in future research and considered together with the surrounding employment opportunities, cultures of migration, existing infrastructure, and land sharing practices.

To conclude, this chapter's findings are innovative as they challenge existing notions of being 'trapped' or immobile (TGOFS 2011) and, consequently, categorizations of environmental migrants (Bates 2002). Furthermore, this study sheds a new light on prevailing theories on environmental migration as it introduces insights from new economics of labour migration and migrant systems theory. This study shows that in order to understand people's migration aspirations, a distinction needs to be made among and within communities between those who have transnational social capital and those who do not (Portes et al. 2002; Eckstein 2010), and even within families, between males and females, young and elderly. Gender appears to play a crucial role in the extent to which people build resilience towards the adverse effects of environmental change. If entire households are affected equally by environmental change, they would more consciously develop household adaptation strategies and spread risks. However, the gendered division of tasks - which may be inspired or shaped by reduced agricultural revenue over time as well - have led to inequalities within the household. In relatively poorer families, and for those working in agriculture, the share of women's contributions in the household incomes decreases over time due to environmental degradation. As a consequence, the status of the women in the family decreases as their dependence on the other household members increases. As the entire household may receive less income due to these changes, the need for migration is especially noted when it concerns the jobs and income of the men in the household and to a lesser extent those of women. Rather, this has translated in the development of intergenerational migration aspirations, of 
mothers wishing their sons would have better opportunities. As noted above, this gender divide and adverse impact of environmental change on gender inequalities is mainly noticeable within lower socioeconomic households, such as those who still need to rely on subsistence economy in agriculture to secure their income. These findings are in line with previous research that found that the consequences of environmental changes are harder felt by people living in particular areas and varies according to social class and gender (TGOFS 2011; Warner et al. 2012) as this means that people experience these changes differently and have distinct vulnerabilities and coping capacities. Finally, as shown by this chapter, it becomes clear that most of these migration aspirations are linked to and understood in terms of employment opportunities.

\section{References}

Bates, D. C. (2002). Environmental refugees? Classifying human migrations caused by environmental change. Population and Environment, 23(5), 465-477. www.jstor.org/stable/27503806.

Berriane M., M. Aderghal, L. Amzil, \& A. Oussi. (2010). Project Paper 4: Morocco. Country and Research Areas Report. EUMAGINE project. International Migration Institute and Université Mohamed V- Agdal, Rabat and Oxford.

Berriane, M., M. Aderghal, \& D. Jolivet. (2012). Project paper 10: Within country analyses: Morocco. EUMAGINE project. International Migration Institute and Université Mohamed VAgdal, Rabat and Oxford.

Carling, J. (2014, September 23-25). The role of aspirations in migration. Paper presented at Determinants of International Migration, International Migration Institute, University of Oxford, Oxford.

Carling, J., \& Hoelscher, K. (2013). The capacity and desire to remit: Comparing local and transnational influences. Journal of Ethnic and Migration Studies, 39(6), 939-958. https://doi. org/10.1080/1369183X.2013.765657.

Crawford, D. (2008). Moroccan households in the world economy. Labor and inequality in a Berber village. Baton Rouge: Louisiana State University Press.

De Haas, H. (2006). Migration, remittances and regional development in southern Morocco. Geoforum, 37(4), 565-580. https://doi.org/10.1016/j.geoforum.2005.11.007.

De Haas, H. (2010). The internal dynamics of migration processes: A theoretical inquiry. Journal of Ethnic and Migration Studies, 36(10), 1587-1617. https://doi.org/10.1080/1369183X.2010. 489361.

Eckstein, S. (2010). Immigration, remittances, and transnational social capital formation: A Cuban case study. Ethnic and Racial Studies, 33(9), 1648-1667. https://doi.org/10.1080/ 01419871003725410.

Faas, A. J. (2016). Disaster vulnerability in anthropological perspective. Annals of Anthropological Practice, 40(1), 14-27.

Gemenne, F. (2010). Migration, a possible adaptation strategy? Institut du développement durable et des relations internationales, $3,1-4$.

Gemenne, F. \& J. Blocher. (2016). How can migration support adaptation? Different options to test the migration-adaptation nexus. Migration, environment and climate change. Working paper IOM. DOI:https://doi.org/10.13140/RG.2.1.2010.6008

Isaakyan, I., \& Triandafyllidou, A. (2017). 'Sending so much more than money': Exploring social remittances and transnational mobility. Ethnic and Racial Studies, 40(15), 2787-2805. https:// doi.org/10.1080/01419870.2016.1259491. 
Kusunose, Y., \& Rignall, K. (2018). The long-term development impacts of international migration remittances for sending households: Evidence from Morocco. Migration and Development, 7 (3), 412-434. https://doi.org/10.1080/21632324.2018.1475383.

Levitt, P. (1998). Social remittances: Migration driven local-level forms of cultural diffusion. International Migration Review, 32(4), 926-948.

Mabogunje, A. L. (1970). Systems approach to a theory of rural-urban migration. Geographical Analysis, 2(1), 1-18.

McLeman, R., \& Gemenne, F. (2018). Environmental migration research. Evolution and current state of the science. In R. McLeman \& F. Gemenne (Eds.), Routledge handbook of environmental displacement and migration (pp. 3-16). London/New York: Routledge.

McPherson, M., Smith-Lovin, L., \& Cook, J. M. (2001). Birds of a feather: Homophily in social networks. Annual Review of Sociology, 27(1), 415-444.

Myrdal, G. (1957). Rich lands and poor. New York: Harper \& Row.

Obokata, R. E., \& Veronis, L. P. (2018). Transnational approaches to remittances, risk reduction, and disaster relief. In R. McLeman \& F. Gemenne (Eds.), Routledge handbook of environmental displacement and migration (pp. 270-277). London/New York: Routledge.

Piguet, E., Pécoud, A., \& De Guchteneire, P. (2011). Migration and climate change: An overview. Refugee Survey Quarterly, 30(3), 1-23.

Portes, A., Guarnizo, L. E., \& Haller, W. J. (2002). Transnational entrepreneurs: An alternative form of immigrant economic adaptation. American Sociological Review, 67(2), 278-298. https://doi.org/10.2307/3088896.

Schewel, K. (2019). Understanding immobility: Moving beyond the mobility bias in migration studies. International Migration Review, 54(2), 328-355. https://doi.org/10.1177/ 0197918319831952.

Schilling, J., Freier, K. P., Hertig, E., \& Scheffran, J. (2012). Climate change, vulnerability and adaptation in North Africa with focus on Morocco. Agriculture, Ecosystems Environment, 156, $12-26$.

Simon, D. H. (2018). Environmental migration in Mexico. In R. McLeman \& F. Gemenne (Eds.), Routledge handbook of environmental displacement and migration. London/New York: Routledge.

Stark, O. (2005). Comment on 'migration and income in source communities: A new economics of migration perspective from China. Economic Development and Cultural Change, 53(4), 983-986.

Stark, O., \& Bloom, D. E. (1985). The new economics of labour migration. The American Economic Review, 75(2), 173-178.

Steinbacher, K. (2015). Drawing lessons when objectives differ? Assessing renewable energy policy transfer from Germany to Morocco. Politics and Governance, 3(2), 34-50. https://doi. org/10.17645/pag.v3i2.192.

The Government Office for Science (TGOFS). (2011). Foresight: Migration and global environmental change future challenges and opportunities. London: The Government Office for Science.

Timmerman, C., Hemmerechts, K., \& De Clerck, H. M.-L. (2014). The relevance of a 'culture of migration' in understanding migration aspirations in contemporary Turkey. Turkish Studies, 15 (3), 496-518. https://doi.org/10.1080/14683849.2014.95474.

Warner, K., Afifi, T., Henry, K., Rawe, T., Smith, C., \& de Sherbinin, A. (2012). Where the rain falls: Climate change, food and livelihood security, and migration (Global Policy Report of the Where the Rain Falls Project). Bonn: CARE France and United Nations University Institute for Environment and Human Security.

Wisner, B., Blaikie, P., Cannon, T., \& Davis, I. (2004). At risk: Natural hazards, people's vulnerability, and disasters (2nd ed.). New York: Routledge.

Zickgraf, C. (2018). Immobility. In R. McLeman \& F. Gemenne (Eds.), Routledge handbook of environmental displacement and migration (pp. 71-84). London/New York: Routledge. 
Open Access This chapter is licensed under the terms of the Creative Commons Attribution 4.0 International License (http://creativecommons.org/licenses/by/4.0/), which permits use, sharing, adaptation, distribution and reproduction in any medium or format, as long as you give appropriate credit to the original author(s) and the source, provide a link to the Creative Commons license and indicate if changes were made.

The images or other third party material in this chapter are included in the chapter's Creative Commons license, unless indicated otherwise in a credit line to the material. If material is not included in the chapter's Creative Commons license and your intended use is not permitted by statutory regulation or exceeds the permitted use, you will need to obtain permission directly from the copyright holder. 